\title{
Histopathological studies on the effects of peroxynitrite on the lungs and trachea of rabbits
}

\author{
A.A. Farshid*, G. Sadeghi-Hashjin", H.R. Ferdowsi*
}

\begin{abstract}
Histopathological studies on the effects of peroxynitrite on the lungs and trachea of rabbits. A.A. Farshid, G. Sadeghi-Hashjin, H.R. Ferdowsi. (C) ERS Journals Ltd 2002. ABSTRACT: Peroxynitrite $\left(\mathrm{ONOO}^{-}\right)$is the reaction product between nitric oxide and the superoxide anion. It is a biological oxidant and cytotoxic anion, produced in vivo, which might cause inflammation and damage to the lungs. This study was designed to investigate whether direct contact with peroxynitrite could cause pathological changes in the airways.

Twenty New Zealand rabbits were divided into four experimental groups. They were anesthetised by intravascular injection of thiopental sodium, and peroxynitrite $(0.5 \mathrm{~mL}$ of a $10 \mathrm{mM}$ solution) was inoculated intratracheally. At $2 \mathrm{~h}, 24 \mathrm{~h}, 48 \mathrm{~h}$, and $72 \mathrm{~h}$ postinoculation trachea and lungs were isolated for histopathology.

The histopathological observations in the lungs were congestion, serous exudation, infiltration of leukocytes and degeneration, which were found to be time-dependent. Changes were similar at 48 and $72 \mathrm{~h}$. Degenerative changes were not progressive. The changes in the trachea were congestion, oedema, leukocyte infiltration, and degeneration of tracheal epithelium.
\end{abstract}

This study shows that peroxynitrite formation in the respiratory tract induces lung inflammation and degenerative changes.

Eur Respir J 2002; 20: 1014-1016.
*Depts of Pathobiology and "Basic Sciences, Faculty of Veterinary Medicine, Urmia University, Urmia, Iran.

Correspondence: G. Sadeghi-Hashjin, P.O. Box 641, Urmia, Iran.

Fax: 984413443442

E-mail: g.sadeghi@mail.urmia.ac.ir

\author{
Keywords: Lungs \\ oxygen radicals \\ pathology \\ peroxynitrite \\ rabbit \\ trachea
}

Received: July 252001

Accepted after revision: April 152002

The Research Office of Urmia University, Urmia, Iran, supported this work.
Peroxynitrite $\left(\mathrm{ONOO}^{-}\right)$is the reaction product between two free radicals, namely, nitric oxide (NO) and the superoxide anion $\mathrm{O}_{2}{ }^{-\cdots}$ :

$$
\mathrm{NO}+\mathrm{O}_{2}^{-} \rightarrow \mathrm{ONOO}^{-}
$$

Peroxynitrite is a potent biological oxidant and inflammatory cells, including macrophages, produce this cytotoxic anion in vivo. Peroxynitrite has been suggested to be the reactive intermediate responsible for some of the pathological conditions associated with an overproduction of nitric oxide $[1,2]$. Peroxynitrite oxidises membrane lipids [3] and tissue sulfhydrils [4], and is believed to damage membrane sodium channels in the lung [5]. Due to these and other mechanisms, it is expected that direct contact with peroxynitrite may cause a wide range of pathological changes in the airways. The present study was designed to investigate this hypothesis and find out whether the rabbit could be a suitable model for this kind of study.

\section{Materials and methods}

\section{Peroxynitrite synthesis}

Peroxynitrite was synthesised in a quenched flow reactor as described previously [6]. Briefly, solutions of $0.6 \mathrm{M} \mathrm{NaNO}_{2}$ and $0.6 \mathrm{M} \mathrm{HCl}$ plus $0.7 \mathrm{M} \mathrm{H}_{2} \mathrm{O}_{2}$ were pumped into a $\mathrm{T}$-junction and mixed in a glass tube. The acid-catalysed reaction of nitrous acid with $\mathrm{H}_{2} \mathrm{O}_{2}$ to form peroxynitrous acid was quenched by pumping $1.5 \mathrm{M} \mathrm{NaOH}$ at the same rate into a second $\mathrm{T}$ junction at the end of glass tubing. The solution was frozen for a week at $-20^{\circ} \mathrm{C}$. As a result of freeze fractionation, peroxynitrite formed a yellow top layer which was retained for further analysis and application. The concentration of peroxynitrite in this layer was determined by absorbance at $302 \mathrm{~nm}\left(\varepsilon_{302}=\right.$ $\left.1.67 \times 10^{3} \cdot \mathrm{M}^{-1} \cdot \mathrm{cm}^{-1}\right)$. Stock solutions of peroxynitrite were kept in a freezer at alkaline $\mathrm{pH}$, and the concentration was determined before each use. At room temperature and at a concentration of $10 \mathrm{mM}$ in Krebs' buffer, peroxynitrite decomposed by 50\%, $92 \%$, and $100 \%$ after 15,30 , and $60 \mathrm{~min}$, respectively.

\section{Animals and the experimental protocol}

Twenty healthy, New Zealand rabbits were selected. The sex of the rabbit was not considered and the animals were in the same weight range. Rabbits were given water and commercial feed $a d$ lib. They were divided into four experimental groups and two animals were taken as control in each group. The rabbits were anesthetised by thiopental sodium $\left(25 \mathrm{mg} \cdot \mathrm{kg}^{-1}\right.$ b.w., i.v.). The site was located and antiseptic solution was applied to the skin, the trachea was then palpated and peroxynitrite $(0.5 \mathrm{ml}$ of $10 \mathrm{mM}$ solution) was inoculated intratracheally using a 
tuberculin syringe. Control animals received distilled water $(0.5 \mathrm{ml})$ intratracheally. The rabbits were sacrificed at intervals of $2,24,48$, and $72 \mathrm{~h}$ postinoculation by an overdose i.v. injection of sodium thiopental. All chemicals used in this study were purchased from Merck (Darmstadt, Germany).

\section{Necropsy and histopathology}

A detailed necropsy was performed, the trachea and lungs were dissected out, and samples for bacteriological cultures were taken from bronchial exudate. The lung and tracheal tissues were fixed in $10 \%$ neutral buffer formaline for histopathology. Sections of $4-5 \mu \mathrm{m}$ were made and stained with haematoxylin and eosin and examined under the light microscope.

\section{Results}

Bacteriological cultures from bronchial exudate were found to be negative for all pathogenic organisms, both in the control and peroxynitrite-treated animals. No gross abnormalities were observed in the control animals. In the peroxynitrite-inoculated animals, pathological changes were limited to the respiratory system. The changes were progressive in nature, that is, from congestion of trachea and lung in the early hours to presence of pneumonic patches. However, no significant differences were observed between the pathological changes at 48 and $72 \mathrm{~h}$ after inoculation.

There were no significant pathological changes in the lungs (fig. 1a) and trachea of the control animals at 2, 24, 48 and $72 \mathrm{~h}$ postinoculation. In the experimental group at $2 \mathrm{~h}$ postinoculation, there was congestion, oedema and leukocyte infiltration in the trachea with some areas of necrosis. Changes in the lungs were focal severe congestion with serous exudation (fig. 1b). Bronchial epithelium showed degenerative changes in some areas. Focal leukocytic infiltration consisting of lymphocytes and neutrophils was also seen.

At $24 \mathrm{~h}$ postinoculation, changes in the trachea comprised more leukocyte infiltration and epithelial necrosis. There was thickening of alveolar septa in the lungs due to congestion and oedema (fig. 1c). Infiltration of leukocytes, mainly lymphocytes, into the alveolar spaces was also seen. Bronchial epithelium showed different degrees of degeneration. At $48 \mathrm{~h}$ postinoculation, there was diffuse leukocytic
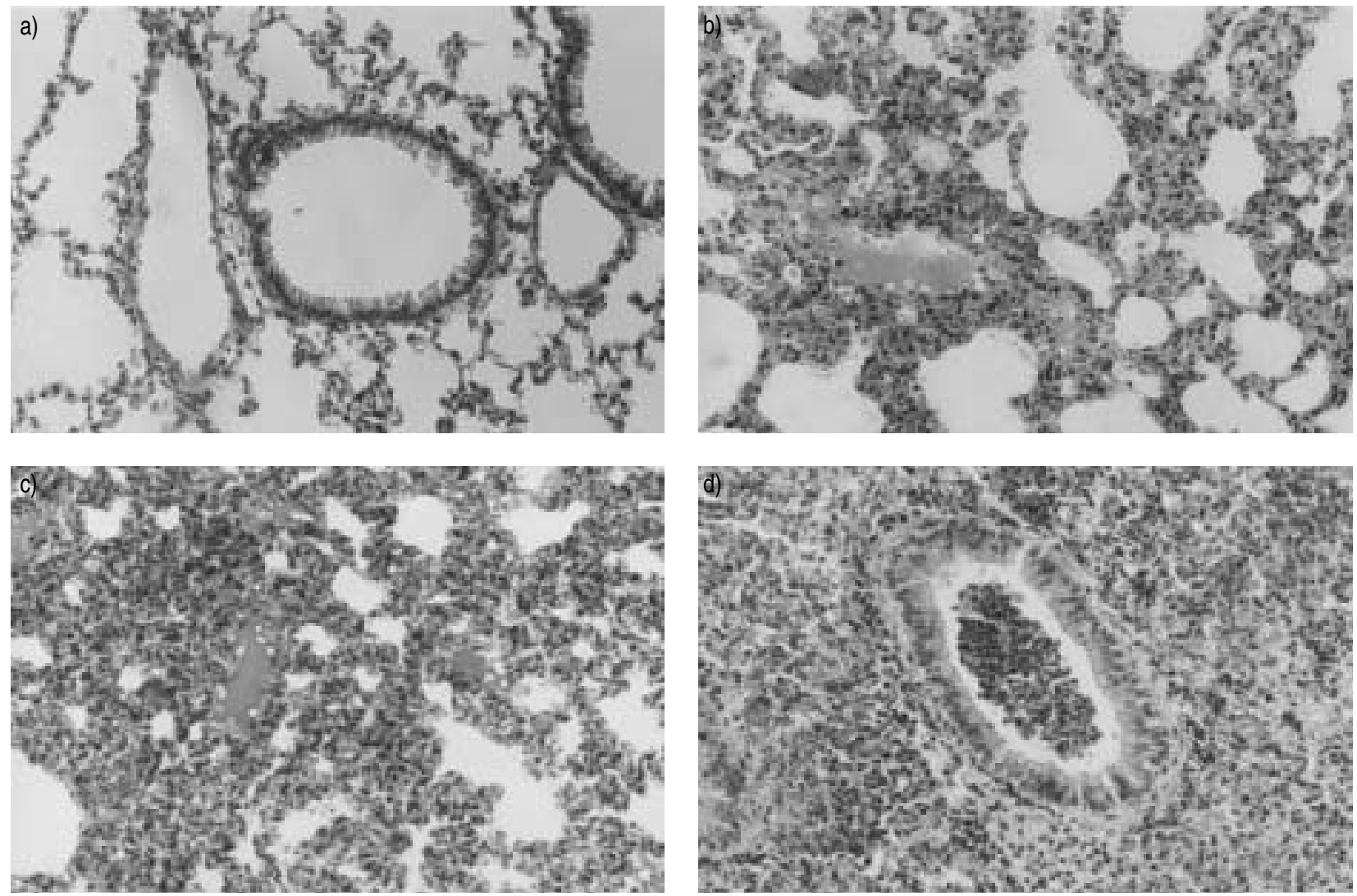

Fig. 1.-a) Micrograph of control rabbit lung, $2 \mathrm{~h}$ after intratracheal instillation of $0.5 \mathrm{~mL}$ distilled water. No evidence of vascular leakage and inflammatory response was observed. b) Micrograph of treated rabbit lung, $2 \mathrm{~h}$ after intratracheal instillation of $0.5 \mathrm{ml}$ of $10 \mathrm{mM}$ peroxynitrite. The anion caused congestion and serious exudation, leading to thickening of alveolar wall. c) Micrograph of treated rabbit lung, $24 \mathrm{~h}$ after intratracheal instillation of $0.5 \mathrm{ml}$ of $10 \mathrm{mM}$ peroxynitrite. Inflammatory reactions with serous exudate are seen in the alveolar spaces. d) Micrograph of treated rabbit lung, $48 \mathrm{~h}$ after intratracheal instillation of $0.5 \mathrm{ml}$ of $10 \mathrm{mM}$ peroxynitrite. Diffuse leukocytic infiltration in the alveolar and bronchial spaces, giving a bronchopneumonia picture. Haematoxylin and eosin staining, $\times 250$. 
infiltration; alveolar spaces were filled with exudate. The cells were neutrophils, lymphocytes and macrophages. Bronchial spaces were filled with leukocytes (fig. 1d). These changes showed a clear picture of bronchopneumonia. The tracheal changes were oedema and leukocytic infiltration and necrosis. Changes at $72 \mathrm{~h}$ postinoculation were similar to those seen at $48 \mathrm{~h}$.

\section{Discussion}

This study shows that a single intratracheal application of peroxynitrite in rabbits may cause inflammatory and degenerative effects in the respiratory tract. In the present study, a high dose of peroxynitrite was administered directly to the airways, causing the severe effects found. Inflammation and tissue damage were observed as rapidly as $2 \mathrm{~h}$ postinoculation. This clearly showed that peroxynitrite could not only bring about an inflammatory reaction but could also induce cell injury. The immediate inflammatory effect was followed by a cellular infiltration during 24,48 , and $72 \mathrm{~h}$ postinoculation, which could be the delayed response to peroxynitrite.

Under (patho)physiological conditions, peroxynitrite could potentially be formed by different cells and hence could bring about similar pathological lesions. The half-life of peroxynitrite has been reported to be only $1 \mathrm{~s}$ at $\mathrm{pH} 7.4$ and $37^{\circ} \mathrm{C}$ [7]. Many inflammatory cells, such as macrophages, produce and release superoxide anions and nitric oxide as part of their microbicidal effector molecules. The simultaneous production of these radicals results in the rapid formation of peroxynitrite [8]. In turn, peroxynitrite oxidises lipids and proteins and via this route cellular activities could be suppressed [2]. SADEGHI-HASHJIN et al. [2] stated that peroxynitrite could be an important factor in tissue injury and chronic inflammatory conditions in which free radicals are released. Such changes probably occur in a nonspecific manner, as similar changes may be observed in the kidney and liver [9]. The serious pathological effects of peroxynitrite could be due to a failure of defence mechanisms against peroxynitrite [1].

There is increasing evidence that peroxynitrite is produced in the respiratory tract, especially by macrophages. It may have a role in the oxidative damage in the lung and might be involved in airway hyperresponsiveness, asthma, pulmonary inflammation, surfactant protein damage, occupational lung disease, adult respiratory distress syndrome, and cigarette smoke-induced pulmonary disorders [2]. Superoxide anion is produced by the airway epithelium in detectable amounts [10]. Peroxynitrite is likely to be produced from the reaction between this substance and nitric oxide. This study shows that peroxynitrite formation in the respiratory tract may be involved in lung inflammation and degenerative changes.

Acknowledgements. The authors are grateful to A. Jamshidi and T. Kahroba for their technical assistance.

\section{References}

1. Muijsers RBR, Folkerts G, Henricks PAJ, SadeghiHashjin G, Nijkamp FP. Peroxynitrite: a two-faced metabolite of nitric oxide. Life Sci 1997; 60: 18331845.

2. Sadeghi-Hashjin G, Folkerts G, Henricks PAJ, Muijsers RBR, Nijkamp FP. Peroxynitrite in airway disease. Clin Exp Allergy 1998; 28: 1464-1473.

3. Rubbo H, Radi R, Trujillo $\mathrm{M}$, et al. Nitric oxide regulation of superoxide and peroxynitrite-dependent lipid peroxidation. Formation of novel nitrogencontaining oxidized lipid derivatives. J Biol Chem 1994; 269: 26066-26075.

4. Radi R, Beckman JS, Bush KM, Freeman BA. Peroxynitrite oxidation of sulfhydryls. The cytotoxic potential of superoxide and nitric oxide. $J$ Biol Chem 1991; 266: $4244-4250$.

5. $\mathrm{Hu} \mathrm{P}$, Ischiropoulos $\mathrm{H}$, Beckman JS, Matalon $\mathrm{S}$. Peroxynitrite inhibition of oxygen consumption and sodium transport in alveolar type II cells. Am J Physiol 1994; 266: L628-L634.

6. Sadeghi-Hashjin G, Folkerts G, Henricks PAJ, et al. Peroxynitrite induces airway hyperresponsiveness in guinea pigs in vitro and in vivo. Am J Respir Crit Care Med 1996; 153: 1697-1701.

7. Marla SS, Lee J, Groves JT. Peroxynitrite rapidly permeates phospholipid membranes. Proc Natl Acad Sci USA 1997; 94: 14243-14248.

8. Denicola A, Rubbo H, Rodriguez D, Radi R. Peroxynitrite-mediated cytotoxicity to Trypanosoma cruzi. Arch Biochem Biophys 1997; 304: 279-286.

9. Sadeghi-Hashjin G, Farshid AA, Najjar-Sadeghi B, Kahroba T, Jamshidi A. Microscopic changes in the liver and kidney, induced by peroxynitrite $\left(\mathrm{ONOO}^{-}\right)$; an in vivo study in the rabbit. In: Abstracts: 14th Iranian Congress of Physiol \& Pharmacol. Tehran, Tehran University of Medical Sciences, 1999; p. 180.

10. Sadeghi-Hashjin G, Henricks PAJ, Folkerts G, Muis T, Garssen J, Nijkamp FP. Role of the epithelial layer in the generation of superoxide anion by the guinea pig isolated trachea. Mediator Inflam 1998; 7: $35-40$. 